\title{
Systemic immunity of chickens with respiratory mycoplasmosis at poultry farms with various production
}

\author{
P. M. Gavrilin ${ }^{1 *}$, N. V. Alekseeva ${ }^{1}$, E. G. Gavrilina ${ }^{1}$, D. A. Korshenko ${ }^{2}$, N. V. Kalashnik ${ }^{2}$, \\ Y. O. Locieva ${ }^{1}$ \\ ${ }^{1}$ Dnipro State Agrarian and Economic University, Dnipro, Ukraine \\ ${ }^{2}$ National Scientific Center "Institute of Experimental and Clinical Veterinary Medicine", Kharkiv, Ukraine \\ *Corresponding author E-mail: morfologagro@gmail.com
}

Received: 15.01.2020. Accepted 15.02.2020

\begin{abstract}
Experimental studies were conducted on the basis of the Research Center for Biosafety and Environmental Control of Resources of the Agroindustrial Complex of the Dnipro SAEU, poultry farms of different directions of productivity of Donetsk-Prydniprovsky region of Ukraine in the period from 2016 to 2019. The purpose of the work is to determine the nature of pathomorphological changes and the status of systemic immunity in chickens with respiratory mycoplasmosis at poultry farms with various production. To determine the immunodeficiency and immunopathological conditions of a productive poultry with respiratory mycoplasmosis, a comprehensive immunological study was performed. Significant fluctuations in the absolute and relative values of leukograms and immunograms have been established, indicating a significant immunological alteration in chickens with respiratory mycoplasmosis. The most significant changes in the status of systemic immunity are found in chickens with respiratory mycoplasmosis at poultry farms with meat production, which are subject to more longer and more intense influence of human activity.
\end{abstract}

Key words: Respiratory mycoplasmosis; Productive poultry; Immunity; Factors of human activity; Immunopathology

\section{Introduction}

Respiratory mycoplasmosis is a factor infectious disease that is not characterized by relay transmission of the pathogen (Dzhupina, 2002). The epizootic process of diseases of this group is governed by the law of stress, and prevention is provided by bringing conditions of retention to the needs of the organism, because due to the constant presence of the pathogen in the body (persistence) specific prevention of the disease is not effective (Aleksyeyeva, 2009; Mathis \& Ackermann, 2016; Shanmugasundaram et al., 2018). The development of immunopathological processes caused by the causative agent of respiratory mycoplasmosis is the ability to damage the endothelium of blood vessels, impaired microcirculation, the formation of microthrombosis, edema and fibrotic degeneration of tissues (Rosengarten et al., 2000; Thilagavathi et al., 2016). It is the impact on the body of birds of various external, including anthropogenic factors, which as synergists activate the pathogenic properties of microorganisms, and leads to clinical manifestation of the disease (Much et al., 2002; Abbas et al., 2018).

One of the most significant negative anthropogenic factors in productive animal husbandry is the complex of breeding and technological components, which are aimed at increasing the growth rate of somatic systems of animals and stimulating the function of reproduction, which directly influences the decrease of immunity. The mechanisms of this decrease are due to the active involvement of lymphocytes in the regulation of the proliferation (growth and development) of cells of nymphoid organs, primarily muscle cells and fibrous connective tissue (Babaeva, 2009; Khariv et al., 2017). An artificial increase in the body's growth rate in the early stages of post-natal ontogeny causes the effect of functional imbalance in the organ system of lymphocytopoiesis and, as a consequence, a decrease in the effectiveness of the factors of immune defense.

As a result, the course of the infectious process in respiratory mycoplasmosis is complicated, and the possibility of rapid disposal of the pathogen, which depends on the efficiency of the immune response of the humoral and cellular type, is reduced (Islam et al., 2011; Prokushenkova, 2014; Ron et al., 2015). Determination of systemic immunity in birds with respiratory mycoplasmosis was caused by the active influence of the pathogen on the protective systems of the macroorganism (Rottem, 2003; Abbas et al., 2018). Superantigenic properties of mycoplasma, cytopathic and cytotoxic effects on macrophages, stimulation of T suppressors negatively affect the formation of the immune response. In addition, several mechanisms of evasion of host immune system factors, the use of antigenic mimicry, and multiple copies of adhesion protein genes have been produced in mycoplasma (Majumder et al., 2014; Majumder \& Silbart, 2016). The use of immunological methods makes it possible to evaluate the state of humoral and cellular immunity by the differential characteristic of the functional activity of $\mathrm{T}$ and $\mathrm{B}$ systems, taking into account the relative and absolute number of circulating lymphocytes (Borkhsenius et al., 2002; Ahmad et al., 2008; Gavrylin et al., 2011). Currently, there are no generally accepted and informative methods of monitoring and diagnosis of the development and condition of bird immune system in poultry farms with various production and intensity of human activity (Khatoon et al., 2018; Muhammad et al., 2018). The influence of mycoplasma and associates on the immune status of the bird organism has not yet been fully disclosed, which is of interest not only to scientists but also to practitioners.

The purpose of the work is to determine the nature of pathomorphological changes and the status of systemic immunity in chickens with respiratory mycoplasmosis at farms with various production. 


\section{Materials and Methods}

Experimental studies were conducted on the basis of the Research Center for Biosafety and Environmental Control of Resources of the Agroindustrial Complex of the Dnipro SAEU, poultry farms of different production of Donetsk-Prydniprovsky region of Ukraine in 2016-2019. The experimental birds were divided into several groups: group I - healthy chickens (control), group II-IV - chickens with respiratory mycoplasmosis (group II - breeding birds, group III - birds from egg production farms, group IV - birds from meat poultry farms). The complex of technological components aimed at increasing the intensity of growth of somatic systems (composition and caloric content of rations, restriction of movement activity, selection for the intensity of weight increase of the apparatus of movement) had the maximum conditional indicators in group IV (egg-meat poultry farms), average in group II (breeding farms) and minimums in group III (egg farms). A comprehensive study of the ill poultry was conducted in order to diagnose respiratory mycoplasmosis, which included the determination of clinical and epizootic data, serological examination (indirect hemagglutination test (IHA)), pathomorphological examination of the dead poultry. To determine the immune status of the sick bird, studies of morphological composition and immunological parameters in 100 samples of stable EDTA blood of chickens (25 samples in each group) were used.

In order to establish characteristic morphological changes in the respiratory mycoplasmosis of chickens, pathomorphological studies of corpses were performed. To detect microscopic changes in the organs, fragments of lungs, heart, kidneys and liver were selected. Samples were fixed in $10 \%$ neutral buffered formalin solution. The fixed specimens were sealed in paraffin (histoplasty) followed by the production of histological sections on a lobe microtome. Histological sections were stained with hematoxylin and eosin (Horalskyi et al., 2013). Histological studies were performed using a Leica DM1000 light microscope (eyepiece 10x, lenses 10x, $40 \mathrm{x})$. Studies of the morphological composition of the blood were performed by a conductometric method and by counting in the Goryaev chamber with determination of the number of red blood cells (RBC), platelets (PLT), leukocytes (WBC). To derive the leukograms, blood smears were treated with Pappenheim: fixed with a solution of eosin methylene blue by May Grunwald and subsequently stained with Romanovsky-Gimza.

Lymphocyte isolation was performed by sedimentation according to A. Bøyum (Bøyum, 1976); determination of the number of Tlymphocytes by the method of spontaneous rosette formation (E-HAND) - according to M. Jondal (Jondal et al., 1993), and Blymphocytes by the method of complementary rosette (EAK-HAND) - according to N. Mendes (Mendes et al., 1973); registration of active T-lymphocytes - by the method of J.K. Novikov (Novikov \& Novikov, 2006). The number of T-helpers (E RUK) and Tsuppressors (E RUK) was determined by theophylline test (Bolotnikov \& Konopatov, 1993), and by comparing the values obtained (E rk RUK/E, etc.). RUC) was calculated index of immunoregulation (IRI). The level of circulating immune complexes (CICs) and their fractional composition according to the PEG-test with fixation of changes on SPC-2 (Karaulov, 2002), and the levels of Ig A, Ig M and Ig G - according to G. Mancini (Bolotnikov \& Konopatov, 1993).

All indicators were presented in absolute and relative values for the purpose of objectification of data and their correct estimation. Exel XP (Microsoft Office) and Statistica for Windows v 6.0 (Statsoft) are used for statistical processing. The mean (M), the error of the mean $(\mathrm{m})$, the criterion of reliability $(\mathrm{t})$, and the value of reliability $(\mathrm{p})$ were calculated. The Student's t-test was used to assess the differences between the chicks of study groups, the differences were considered significant at $p \leq 0.05$.

\section{Results and Discussion}

In determining the epizootic status in poultry farms with different directions of productivity, it was established that the clinical manifestation of respiratory mycoplasmosis begins from the 20-days age in chickens of the meat production, and in chickens from breeding and egg production farms - from the 30-days age. Characteristic clinical signs of respiratory mycoplasmosis in chickens were depression, swelling and hyperemia of infraorbital sinuses, serous fibrinous conjunctivitis, tracheal wheezing, and cough. The results of a serological study of an indirect hemagglutination test (IHA) with a specific MG (Mycoplasma gallisepticum) antigen have yielded positive results.

As a result of the pathological anatomical section of chickens suffering from respiratory mycoplasmosis, it was found that the main morphological changes were found in the respiratory organs and did not depend on the production of the poultry farm.

The corpses of the chickens are in the state of cachexia, comb, earrings, earlobes are blue. Around the nasal openings there are crusts of fibrinous exudate, infraorbital sinuses (45\%) swollen, hyperemic, filled with fibrinous masses (Figure 1a). The mucous membrane of the trachea is hyperemic, sharply swollen, pierced with hemorrhage.

At the initial stage of the disease on the surface of the mucous membrane contains a transparent serous exudate (23\%), which subsequently becomes catarrhal, turbid and sticky (57\%), and then - fibrinous (20\%). Some chickens (27\%) with serous fibrinous exudate have blocked nasal passages. At the autopsy, one - $(17 \%)$ and bilateral $(83 \%)$ lung lesions were established. The most commonly reported lesions were those parts of the lung that were in contact with the air sacs. The lungs were in a state of acute catarrhal-fibrinous pneumonia (Figure 1b). Single or multiple necrotic foci were found in the lung parenchyma, ranging in size from $1 \mathrm{~mm}$ to $5 \mathrm{~mm}$. In the long course of the disease, encapsulation and sequestration of necrotic foci were recorded. In the lumen of the bronchi were found clumps of fibrinous exudate in the form of plugs. Only $5 \%$ of the studied poultry found congestive hyperemia and pulmonary edema (Figure $2 \mathrm{a}$ ).

In $95 \%$ of dead poultry expressed fibrinous pleurisy (Figure $2 b$ ) was established. They found a characteristic of respiratory mycoplasmosis sign - the infection of the air sacs. The walls of the bags are dull, their cavities filled with serous-fibrinous exudate. Fibrinous masses are dense, yellowish in color, easily separated from the underlying tissue. In $13 \%$ of poultry, the air sacs germinated with granulation tissue. 

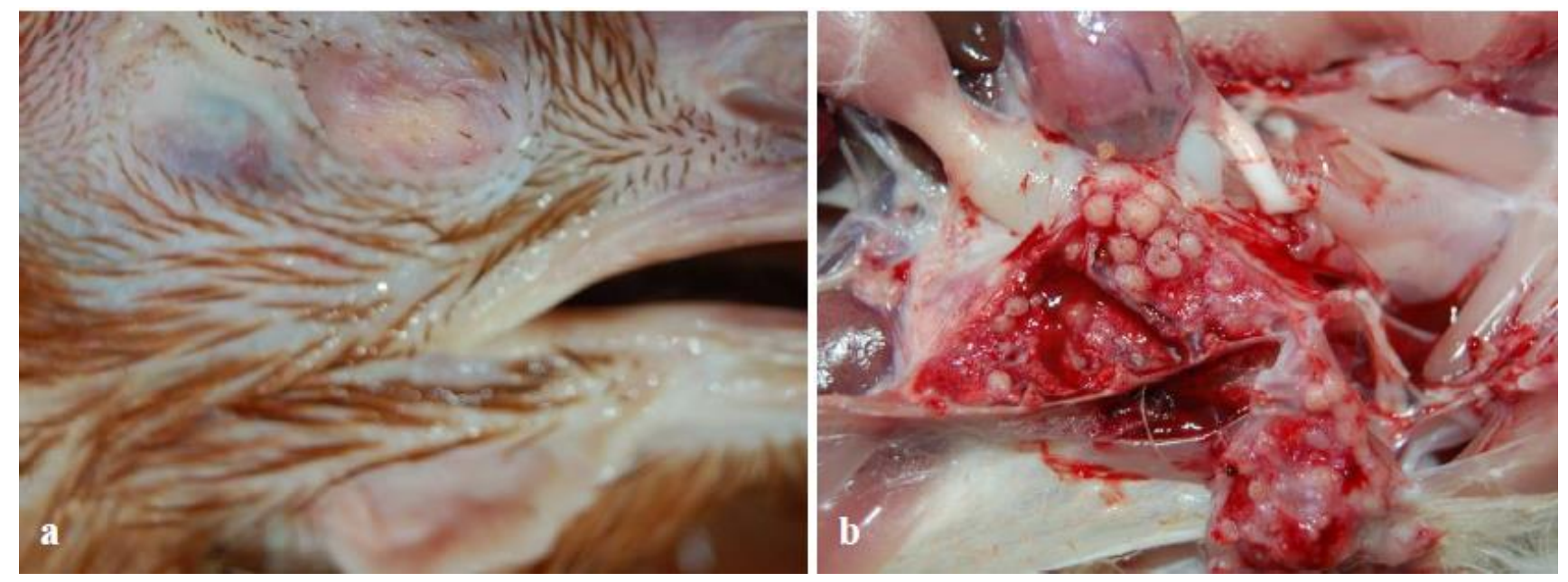

Figure 1. Pathological changes in the body of chickens with respiratory mycoplasmosis: a) fibrinous sinusitis, b) acute catarrhalfibrinous pneumonia with foci of necrosis.
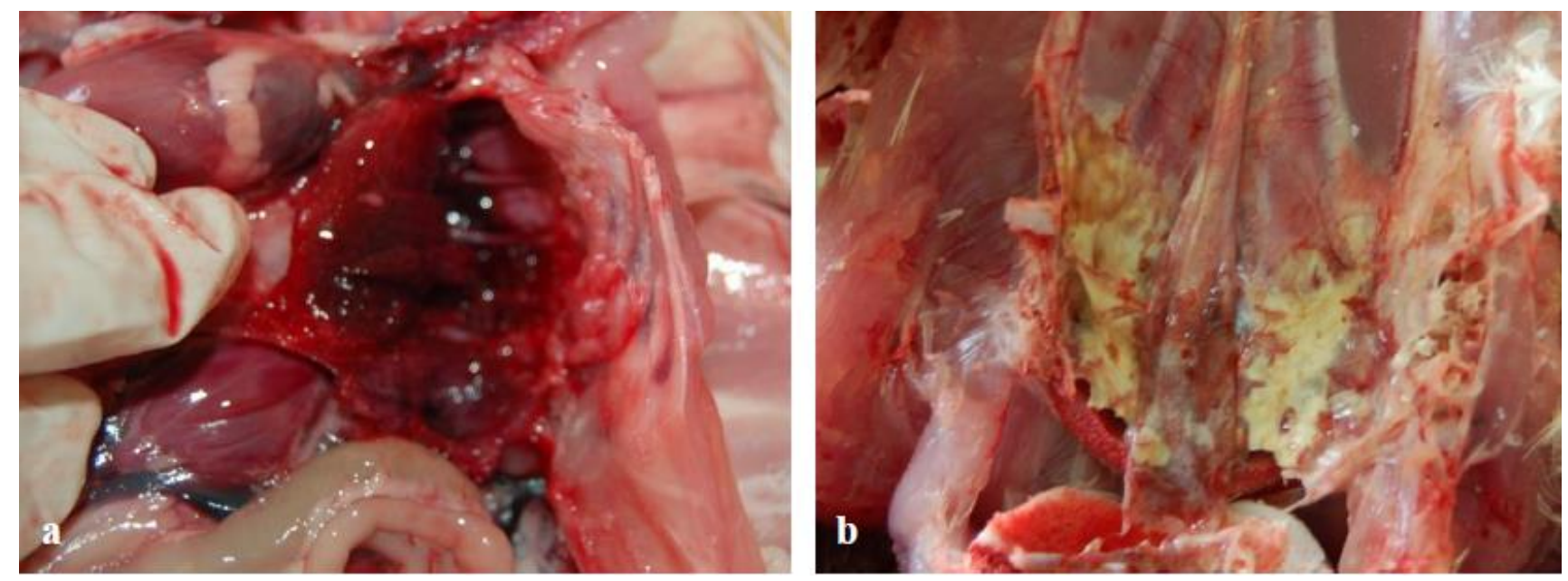

Figure 2. Pathological changes in the body of chickens with respiratory mycoplasmosis: a) congestive hyperemia and pulmonary edema, b) fibrinous pleurisy

In $78 \%$ of chickens, signs of nephro-nephritis (Figure 3a) were recorded, in which the kidneys were pale, enlarged, and the parenchyma flabby, sometimes containing hemorrhage (Figure 3b). In other organs changes are less characteristic. In the heart, plethora of coronary vessels, fibrinous pericarditis (32\%) were recorded. Myocardium in a state of dystrophy - flaccid, gray, sometimes (7\%) contains necrotic foci of white-gray or yellowish-gray. The spleen is enlarged, the ovaries are poorly developed.
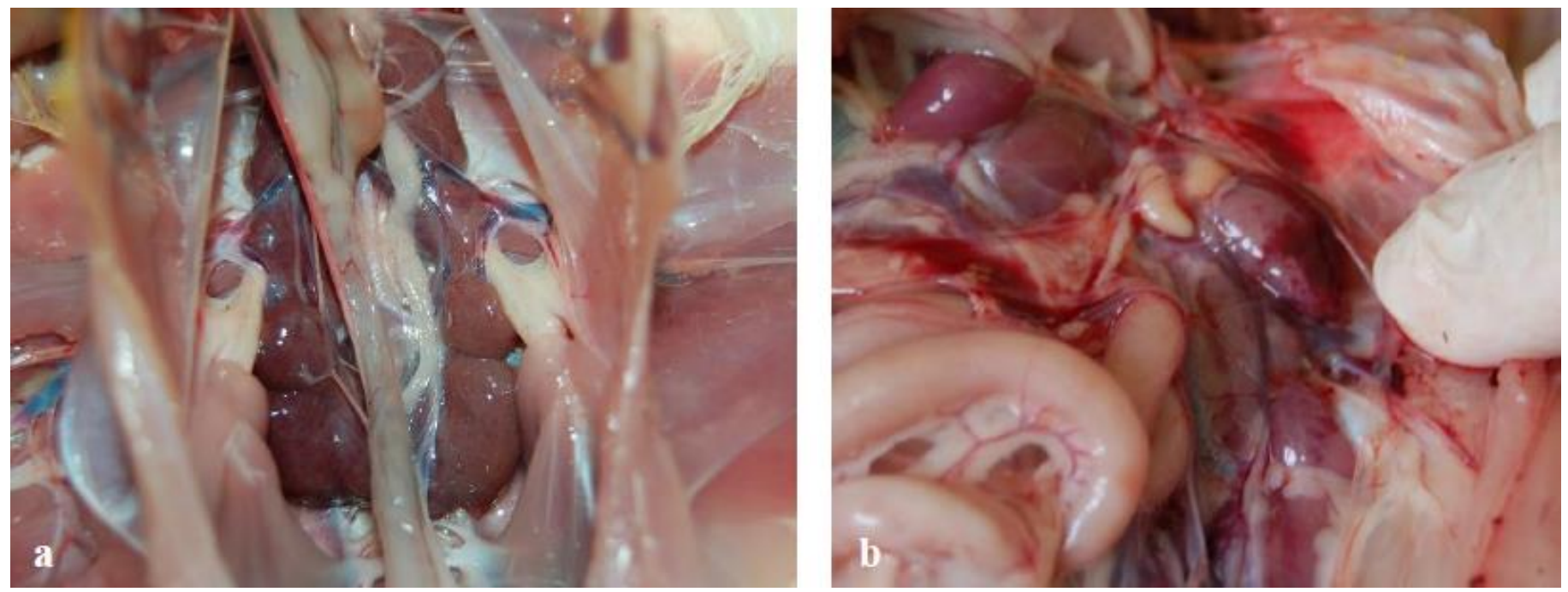

Figure 3. Pathological and anatomical changes in the body of chickens with respiratory mycoplasmosis: a) nephrosis-nephritis, b) hemorrhage in the kidney parenchyma. 
At the histological level, the manifestations of congestive hyperemia, edema, areas of catarrhal-fibrinous pneumonia, significant lymphoid-macrophage infiltration of the affected areas were established in the lungs of the sick poultry (Figure 4a). In the heart, fibrinous pericarditis with lymphoid-macrophage infiltration of necrotized cardiomyocytes, myocardial dystrophy (protein myocardial dystrophy). In renal parenchyma congestive hyperemia, acute serous glomerulonephritis, local necrosis of the renal tubule epithelium, protein dystrophy of the renal tubule epithelium (Figure 4b).

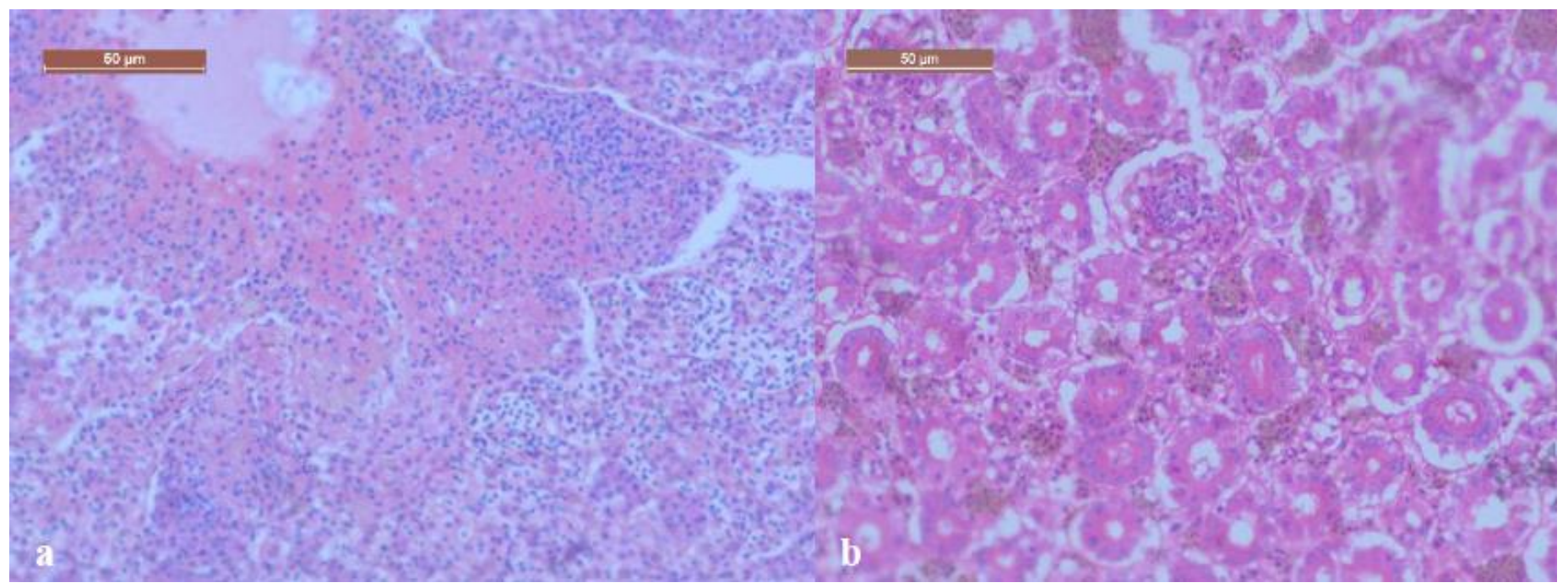

Figure 4. Histological sections from the organs of the victims of respiratory mycoplasmosis of chickens: a) lungs - areas of catarrhal-fibrinous pneumonia, b) kidneys - acute serous glomerulonephritis, necrosis of the epithelium of the renal tubules. Hematoxylin and eosin. 400x.

In the liver, congestive hyperemia, local necrosis of hepatocytes, protein-fat hepatodystrophy, fibrinous (fibrous) perigepatitis is expressed. The results of pathohistological studies show that the main pathology in patients with respiratory mycoplasmosis of chickens is fibrinous, catarrhal-fibrinous lesions of organs: lungs (fibrinous-purulent pneumonia) and serous membrane of the thoracic cavity, and inflammation of the organs pericardium (fibrinous (fibrous) pericarditis). The immune status of the patient with respiratory mycoplasmosis of the poultry was determined by the results of the study of the morphological composition of the blood and the analysis of immunological parameters (Tables 1 and 2). In the study of the morphological composition of blood of chickens in poultry farms of different productivity, it was found that the erythrocyte count (RBC) was normal, but there was a decrease in group II, III platelet count (PLT) and an increase in group II-IV leukocyte (WBC) level compared to the control.

An increase in the absolute number of leukocytes in the peripheral blood of chickens of both breeding and commercial poultry by $50-80 \%$ was noted. Chickens with respiratory mycoplasmosis in poultry farms of meat production increase in all absolute parameters of leukogram, and in farms of breeding production decrease only in the level of mature heterophiles - by $65 \%$ compared with control. We refgistered the increase in all the absolute indicators of leukocyte formula, the largest deviations were observed in egg farms: egg basophils increased by 6.5 times, monocytes - by 1.9 times; in meat farms the eosinophils increased by 2.5 times, lymphocytes - by 1.8 times. In the leucoformula blood of breeding birds there is a significant increase by 6.2 times in the absolute number of young heterophiles, and in the chickens from egg production farms this number decreased (shift to the right), in comparance to control.

Table 1. Blood leucogram of 30-day-old chickens from poultry farms of different production, $M \pm m,(n=25)$.

\begin{tabular}{|c|c|c|c|c|}
\hline Parameters & Group 1 & Group 2 & Group 3 & Group 4 \\
\hline WBC $\left(10^{9} \mathrm{~L}^{-1}\right)$ & $5.78 \pm 0.72$ & $8.63 \pm 1.08^{*}$ & $8.79 \pm 1.10 *$ & $10.34 \pm 1.29 *$ \\
\hline Lymphocytes, abs & $4.23 \pm 0.32$ & $5.35 \pm 0.23 *$ & $6.39 \pm 0.49 *$ & $7.67 \pm 0.67 *$ \\
\hline Lymphocytes, \% & $73.2 \pm 5.54$ & $62.0 \pm 2.67 *$ & $72.7 \pm 5.43^{*}$ & $74.2 \pm 6.48^{*}$ \\
\hline Monocytes, abs & $0.10 \pm 0.01$ & $0.13 \pm 0.04 *$ & $0.19 \pm 0.03 *$ & $0.11 \pm 0.05^{*}$ \\
\hline Monocytes, \% & $1.7 \pm 0.16$ & $1.5 \pm 0.46^{*}$ & $2.1 \pm 0.33^{*}$ & $1.1 \pm 0.48^{*}$ \\
\hline Basophils, abs & $0.08 \pm 0.02$ & $0.14 \pm 0.03 *$ & $0.52 \pm 0.09 * * *$ & $0.16 \pm 0.03^{*}$ \\
\hline Basophils, \% & $1.4 \pm 0.35$ & $1.6 \pm 0.34^{*}$ & $5.9 \pm 1.02 * * *$ & $1.5 \pm 0.28^{*}$ \\
\hline Eosinophils, abs & $0.31 \pm 0.04$ & $0.35 \pm 0.05^{*}$ & $0.57 \pm 0.08^{*}$ & $0.76 \pm 0.09 *$ \\
\hline Eosinophils, abs\% & $5.5 \pm 0.69$ & $4.1 \pm 0.59 *$ & $6.5 \pm 0.63^{*}$ & $7.4 \pm 0.88^{*}$ \\
\hline Heterophils young, abs & $0.45 \pm 0.07$ & $2.29 \pm 0.02 * *$ & $0.49 \pm 0.18^{*}$ & $0.86 \pm 0.14 *$ \\
\hline Heterophils young, \% & $7.8 \pm 1.21$ & $26.5 \pm 1.31 * *$ & $5.6 \pm 2.47^{*}$ & $8.3 \pm 1.35^{*}$ \\
\hline Heterophils mature, abs & $0.61 \pm 0.08$ & $0.37 \pm 0.08^{*}$ & $0.63 \pm 0.19 *$ & $0.78 \pm 0.11^{*}$ \\
\hline Heterophils mature, \% & $10.5 \pm 1.38$ & $4.3 \pm 0.93 *$ & $7.2 \pm 2.21 *$ & $7.5 \pm 0.96 *$ \\
\hline
\end{tabular}

Here and in Table 2: * $p<0.05, * * p<0.01, * * * p<0.001$ differences were statistically significant when compared to controls (group I); group I healthy chickens, groups II-IV - chickens suffering from respiratory mycoplasmosis, group II - breeding, group III - egg production, group IV meat production. 
The relative indicators of the leuco-formulas in chickens from poultry farm of meat production also indicate a significant basophilia with a significant increase in the indicator compared to the control, indicating the presence of infections or inflammation. In chickens of other poultry farms, there has also been an increase in the relative number of basophils.

It is well known that when an infection or inflammatory process occurs in the body, the bone marrow actively produces immature heterophiles and by their quantity in the blood determine the presence of a bacterial infection and conclude its activity in the body. Increase in heterophil activity compared to control by $68.3 \%$ was established in chickens of breeding poultry. Relative heterophilosis with a rod-shift (shift of the leukocyte formula to the left) is typical for bacterial infections (Bolotnikov \& Konopatov, 1993; Karaulov, 2002; Aleksyeyeva, 2009). The number of rod-core heterophiles was increased 3.4-fold, indicating bone marrow activity.

Chickens of commercial poultry farms, on the contrary, have relative heteropenia, which is most pronounced in chickens in the egg production. A decrease of $28.2 \%$ and $31.4 \%$, respectively, of rod-and-segment heterophiles was observed. In poultry farms of meat production there was a significant decrease in segmental heterophiles by $28.6 \%$ (shift of leukocyte formula to the left) against moderate heteropenia. The establishment of heteropenia indicates a suppression of hematopoiesis in the bone marrow or increased destruction of heterophiles, indicating a decrease in immunity activity. High- and medium-degree relative monocytopenia was established in chickens in livestock and breeding poultry with a $35 \%$ and $11.8 \%$ decrease in the number of monocytes, respectively, which also indicates a decrease in immunity and a rather low level of reactivity of the organism against internal and external pathogens. On the contrary, the chickens from the farms with egg production had high-grade relative monocytosis, with a $25.5 \%$ increase in the number of monocytes. The absolute number of eosinophils is increased in the blood of chickens of all poultry farms compared to control, and the relative number of eosinophils decreased in chickens of breeding poultry. The main function of eosinophils is to form a special barrier aimed at protecting the body against infection by activating the receptors responsible for immunity in cells. Eosinophilia is a kind of marker of pathological changes in the body. There is a confirmed correlation of the level of eosinophils in the blood to the severity of the pathological process in the body of patients. Eosinophils are capable of destroying a foreign protein in the body, absorbing it and dissolving it with their enzymes. The decrease in the concentration of eosinophils in the blood indicates a suppression of bone marrow, which is more often observed in infectious diseases at the initial stage or in the acute phase.

The results of the leukogram indicate that eosinopenia and heterophilosis with shift of the leucoformula to the left have been registered in the chickens of breeding poultry farm; in chickens of egg production farms we registered basophilia, monocytosis and heteropenia with shift of leucoformula to the right, and in the chickens of meat production farms we revealed the monocytopenia, eosinophilia and heteropenia with shift of leucoformula to the right.

The cellular level of immunity is characterized by the content of T-total lymphocytes, T-active lymphocytes, T-helpers, Tsuppressors, NK-cells and the calculated immunoregulatory index (IRI) (Kysera et al., 2018; Rudenko et al., 2019; Kisera et al., 2019). We found that in the peripheral blood of chickens of the II and IV groups there was an increase in the absolute and relative number of the population T of total lymphocytes, including T-active and a subpopulation of T helper. Increased T-lymphocyte count, testify to immunity activity, and increased expression of T-active lymphocytes indicates the severity and strength of the immune response. These rates were higher in Chickens II and IV, as was the estimated IRI. The immunoregulatory index did not decrease below 1 to indicate immunodeficiency and did not increase above 2.5 to indicate immunoreactivity of the organism, although this figure was in the upper limits of 2.31 and 2.5, respectively, in chickens of II and IV groups. The data obtained indicate stimulation of the immune system by mycoplasma antigens. The relative values of the number of T suppressors, in contrast to absolute, on the contrary indicate their decrease in the blood of chickens of all three experimental groups in comparison with the control.

Table 2. Immunogram of blood of 30-day-old chickens from poultry farms of different production, $M \pm m,(n=25)$.

\begin{tabular}{lllll}
\hline Parameters & Group I & Group II & Group III & Group IV \\
T-general, abs & $0.94 \pm 0.04$ & $1.59 \pm 0.11^{*}$ & $1.51 \pm 0.09^{*}$ & $1.96 \pm 0.15^{*}$ \\
T-general, \% & $22.2 \pm 0.94$ & $29.7 \pm 2.05^{*}$ & $23.6 \pm 1.41^{*}$ & $25.6 \pm 1.96^{*}$ \\
T-active, abs & $0.39 \pm 0.06$ & $0.73 \pm 0.11^{*}$ & $0.67 \pm 0.06^{*}$ & $0.94 \pm 0.14^{*}$ \\
T-active, \% & $41.5 \pm 6.38$ & $45.9 \pm 6.92^{*}$ & $44.4 \pm 3.98^{*}$ & $47.9 \pm 7.13^{*}$ \\
T-helpers, abs & $0.51 \pm 0.03$ & $1.11 \pm 0.08^{*}$ & $0.84 \pm 0.05^{*}$ & $1.40 \pm 0.17^{*}$ \\
T-helpers, \% & $54.2 \pm 3.19$ & $69.8 \pm 5.03^{*}$ & $55.6 \pm 3.31^{*}$ & $71.4 \pm 8.67^{*}$ \\
T-suppressor, abs & $0.43 \pm 0.02$ & $0.48 \pm 0.05^{*}$ & $0.67 \pm 0.07^{*}$ & $0.56 \pm 0.09^{*}$ \\
T-suppressor, \% & $45.8 \pm 2.13$ & $30.2 \pm 3.15^{*}$ & $44.4 \pm 4.64^{*}$ & $28.6 \pm 4.59^{*}$ \\
Immunoregulatory index (IRI) & $1.16 \pm 0.03$ & $2.31 \pm 0.06^{*}$ & $1.25 \pm 0.05^{*}$ & $2.50 \pm 0.13^{*}$ \\
NK-cells, abs & $2.91 \pm 0.27$ & $3.04 \pm 0.14^{*}$ & $4.41 \pm 0.38^{*}$ & $4.57 \pm 0.45^{*}$ \\
NK-cells, \% & $68.9 \pm 6.39$ & $56.8 \pm 2.62^{*}$ & $69.1 \pm 5.95^{*}$ & $59.5 \pm 5.86^{*}$ \\
B-lymphocytes, abs & $0.38 \pm 0.07$ & $0.72 \pm 0.07^{*}$ & $0.47 \pm 0.03^{*}$ & $1.14 \pm 0.1^{* *}$ \\
B-lymphocytes, \% & $8.9 \pm 1.64$ & $13.5 \pm 1.31^{*}$ & $7.3 \pm 0.47^{*}$ & $14.9 \pm 1.31^{*}$ \\
Ig A, mg/l & $0.34 \pm 0.02$ & $0.53 \pm 0.02^{*}$ & $0.35 \pm 0.05^{*}$ & $0.44 \pm 0.03^{*}$ \\
Ig G, mg/l & $1.23 \pm 0.18$ & $1.39 \pm 0.14^{*}$ & $1.43 \pm 0.23^{*}$ & $1.44 \pm 0.15^{*}$ \\
Ig M, mg/l & $0.43 \pm 0.06$ & $0.57 \pm 0.05^{*}$ & $0.49 \pm 0.06^{*}$ & $0.55 \pm 0.03^{*}$ \\
CIC general (CIC $)$ & $17.6 \pm 3.06$ & $36.7 \pm 6.76^{*}$ & $93.2 \pm 20.88^{* * *}$ & $47.8 \pm 4.27^{*}$ \\
CIC big (CIC, & $7.3 \pm 1.17$ & $13.1 \pm 2.41^{*}$ & $6.4 \pm 0.4 *$ & $4.1 \pm 0.63^{*}$ \\
CIC medium (CIC ) & $6.2 \pm 1.11$ & $7.8 \pm 1.77^{*}$ & $14.4 \pm 1.63^{*}$ & $6.4 \pm 0.40^{*}$ \\
CIC small (CIC ) & $4.1 \pm 1.26$ & $15.8 \pm 3.09^{*} *$ & $72.4 \pm 19.17^{* * *}$ & $37.3 \pm 4.26^{* * *}$ \\
\hline
\end{tabular}

The NK cell population in the blood of II and IV chickens was reduced by $17.6 \%$ and $13.6 \%$, respectively, and slightly increased in group III chickens. The decrease in the number of NK cells indicates an immunodeficiency state as they are responsible for the lysis of target cells infected with intracellular antigens. The humoral level of immunity is characterized by the content of B-lymphocytes, as well as the level of immunoglobulins of different classes (Ig A, Ig G, Ig M) and circulating immune complexes (CICs).

The absolute B-lymphocyte count was increased in the blood of chickens of all three study groups, and the relative B-lymphocyte count only in chickens of II and IV groups by $51.7 \%$ and $67.4 \%$, respectively, and chickens of group III on the contrary decreased by $18 \%$. in relation to the control group. B-lymphocytes are derivatives of plasma cells that are directly involved in the production of 
immunoglobulins. As a result of our research, the blood of chickens in the II and IV groups showed an increase in both B lymphocytes and immunoglobulins. High levels of Ig A and Ig $M$ have been established and smaller Ig G. Ig A (secretory) binds bacteria on the mucosal surface, preventing the pathogen from entering the internal environment of the body. Ig $M$ is the earliest marker of respiratory mycoplasmosis, it is from IgM synthesis that the body's immune response begins and its high concentrations are recorded during periods of acute inflammatory process. Ig $\mathrm{G}$ is a serological marker of a current or recently transmitted disease and is typically synthesized by memory cells in the final phase of the immune response.

In the blood of chickens of all experimental groups we observed 2.1-5.3 times increase in the level of immune complexes in the vast majority (43-78\%) due to CICs and CICm. Normally, the immune complexes that are formed in the bloodstream are phagocytosed and destroyed, but in our case, an excess of them is formed, which is characteristics of the acute course of the disease when the rate of their formation prevails over the rate of elimination.

According to the results of our research, it was found that clinically respiratory mycoplasmosis began to appear earlier in chickens of meat direction farms (on the 20th day), later among the chickens of breeding and egg production (on the 30th day). Some other researchers also point to the early infection of chickens and the manifestation of the characteristic of respiratory mycoplasmosis symptoms. Thus, Georgiades G.K. (2002) reported ated in the study of the serum of daily broiler chickens antibodies to MG were isolated in $21.27 \%$ of the samples. Ahmad et al. (2008) reported high rate of MG 6 infection of 23 week old breeding poultry farms was noted $-74.6 \%$. Moreover, the presence of antibodies to MG was not always consistent with the manifestation of clinical signs of the disease. Muhammad et al. (2018) in the study ELISA method of serum from birds with characteristic of respiratory mycoplasmosis clinical signs, stated that $72 \%$ of samples were positive for the presence of antibodies to MG, and from clinically healthy birds $28 \%$ of samples. Khatoon et al. (2018). also indicates a high infection rate of MG chickens in commercial poultry. In the study of pathological material from 124 chickens by PCR (tracheal tissue, air sacs, lungs), $40.32 \%$ of the samples were positive. Other researchers have compared the prevalence of seroprevalence to MG among poultry in different performance areas by ELISA. The highest seropositivity was established in the poultry-egg production direction $-64 \%$ and breeding - 58\%, and the lowest in broilers - 37\% (Abbas et al., 2018). In India, in the study of blood serum of broiler chickens by the indirect ELISA method, the total seroprevalence of MG was $16.31 \%$ : among four weekly chickens - $18.18 \%$, five weekly chickens - $5.66 \%$, six weekly chickens $27.27 \%$ (Shanmugasundaram et al., 2018). Studies conducted by Abbas et al. (2018). in poultry farms of different performance areas indicated the presence of a large number of ELISA-positive for MG sera of $42.79 \%$ of 846 chickens with respiratory pathology. Moreover, from the material from the ELISA-positive bird was able to cultivate MG almost 50\% of the samples, indicating active infection. Clinically, in poultry, respiratory mycoplasmosis, as well as the results of our studies, showed a variety of signs: cough, sneezing, shortness of breath, conjunctivitis, the presence of foamy discharge from the nose and eyes. Macroscopic and microscopic changes in organs and tissues consisted of swelling of the tracheal epithelium and the presence of necrosis, loss of the eyelashes and mucous layer covering the entire trachea. In the lungs, congestion, hemorrhage, focal necrosis, and leukocyte infiltration, especially due to lymphocytes (Borkhsenius et al., 2002; Rottem, 2003; Islam et al., 2011; Majumder et al., 2014; Ron et al., 2015; Majumder \& Silbart, 2016; Mathis \& Ackermann, 2016; Thilagavathi et al., 2016; Abbas et al., 2018; Khatoon et al., 2018; Muhammad et al., 2018). In studying the immune status of 30-day-old chickens in patients with respiratory mycoplasmosis, we established the prevalence of the cellular level of immunity. The results of our studies coincide with those of other researchers who claim that this occurs in the diagnosis of atypical pathogens (mycoplasma, chlamydia), bacterial infections with the intracellular presence of the pathogen (mycobacterium), viral and fungal pathogens. Because the humoral level of immunity prevails in bacterial infections with extracellular pathogen (Borkhsenius et al., 2002; Karaulov, 2002; Novikov \& Novikov, 2006; Ahmad et al., 2008; Horalskyi et al., 2013).

The results of the hematological examination indicate that the leukocyte level in the chickens of all experimental groups in relation to the control group is 1.49-1.79 times, which is mainly due to the growth of lymphocytes and possibly due to the mobilization of the body's defense systems (Rottem, 2003; Majumder \& Silbart, 2016). This is a kind of indicator of bone marrow irritation due to its functional failure. The bone marrow compensates for the death of mature heterophiles in the fight against intoxication and gives all the immature forms in the bloodstream along with the mature (Novikov \& Novikov, 2006; Babaeva, 2009). The analysis of the absolute and relative indices of the leuco-formulas of chickens of breeding poultry farms indicates heterophilosis and eosinopenia. Because of heterophiles protect the body against any type of infection, so increasing them indicates the presence of chickens in the infectious process. Reducing the level of eosinophils signals a decrease in the body's defenses and a decrease in its resistance to adverse factors. Other researchers indicate that the main function of eosinophilic granulocytes is to inactivate immune complexes (Bolotnikov \& Konopatov, 1993; Karaulov, 2002).

According to the analysis of blood leukograms of chickens from egg production poultry farm, we have found an increase in the level of basophils observed in infectious diseases and high-grade heteropenia indicates severe pathology. The main reason for the high levels of monocytes in the blood of chickens is the adequate response of the organism, which tries to protect itself by increasing the activity of special cells endowed with the functions to absorb and transform morbid microorganisms. In addition, basophils, through their specific heparin-containing granules, inactivate histamine, which acts as an inflammatory hormone (Karaulov, 2002; Mathis \& Ackermann, 2016). In broiler chickens, relative blood leukograms indicate an increase in eosinophils and a decrease in monocytes. Monocytopenia indicates a significant severity of the infectious process, and eosinophilia indicates that the body fights infection (Bolotnikov \& Konopatov, 1993; Borkhsenius et al., 2002).

The increase in the level of $\mathrm{T}$ and $\mathrm{B}$ lymphocytes, as well as antigen-binding lymphocytes in peripheral blood of chickens, established by us, testifies to the adequate response of the immune system of the bird organism to the penetration of the antigen, which according to some researchers is one of the favorable prognostic features of the formation of immune (Karaulov, 2002; Rottem, 2003; Novikov \& Novikov, 2006). The most significant changes in the results of our studies occur in the subpopulation of Tactive lymphocytes - their number in the blood of chickens in the experimental groups relative to the control increased by $1.71-2.4$ times, and T helper increased in 1.65-2.74 times. When comparing the indicators of cellular immunity, which were characterized by an increase in the number of EA-RUK, E-RUK. The highest diagnostic value is the immunoregulatory index (IRI). According to many researchers, in the presence of an inflammatory process that goes without complications, IRI is reduced (Bolotnikov $\&$ Konopatov, 1993; Novikov \& Novikov, 2006; Majumder \& Silbart, 2016). The results of our studies show the opposite result - in the blood of chickens of the three study groups, compared to the control IRI increased by 1.1-2.2 times. 
Evidence of the content of immunoglobulins in the serum of chickens in patients with respiratory mycoplasmosis is very diverse. Some researchers point to a local deficiency of secretory IgA in the bronchi, which may be offset by the synthesis of IgM and IgG. In turn, Ig G activates platelets and also affects their functional properties (Mendes et al., 1973; Borkhsenius et al., 2002; Ahmad et al., 2008). Other researchers report the important role of IgA in the formation of local immunity, and cellular immunity provides a systemic response of the body (Bolotnikov \& Konopatov, 1993; Karaulov, 2002; Novikov \& Novikov, 2006; Majumder \& Silbart, 2016). The results of our studies indicate a significant increase in IgA and IgM in the blood of chickens in all three study groups, especially breeding poultry farms - by $55.8 \%$ and $32.6 \%$ respectively and cattle meat productivity by $29.4 \%$ and 27 , respectively. $9 \%$ respectively. The IgG level in the blood of the test group chickens although increased compared to the control, but this increase did not rise above $17.0 \%$. When antigen and antibody interact, circulating immune complexes (CICs) are formed. The level of CIC in respiratory diseases is directly dependent on the concentration of the antigen. At the optimal level of antibodies large, nonpathogenic CICs are formed. In the absence of antibodies, small and medium-sized CICs are formed, in which pathogens can retain their viability and, once the complex is destroyed, infect cells again. Small and medium CICs are in the blood for a long time, poorly phagocytosed by macrophages: able to activate the complement system and fixate on the endothelium. The most pathogenic are considered to be medium molecular weight, capable of initiating a chain of successive immunopathological processes at high concentrations (Bolotnikov \& Konopatov, 1993; Novikov \& Novikov, 2006). The results of our studies indicate an increase in the number of CICs in the blood of chickens of all experimental groups with prevalence of small and medium. This, we registered 2.08 increase in chickens from breeding production farms, 5.29 increase in chickens from egg production farms, and 2.71 time increase in chickens from meat production farms. Also, an increase in pathogenic CIC indicates disorders in the functioning of polymorphonuclear leukocytes and the complement system (Borkhsenius et al., 2002; Karaulov, 2002).

In addition, circulating immune complexes can significantly affect the severity of the immune response: suppress the response of $T$ cells to different mitogens, weaken the activity of T-helper cells and stimulate the function of T-suppressors (Bolotnikov \& Konopatov, 1993; Karaulov, 2002; Novikov \& Novikov, 2006).

\section{Conclusion}

Mycoplasma is a conditionally pathogenic agent that, under intense anthropogenic pressure, exhibits its pathogenic properties, which are realized in several stages: from the pre-immune response (inflammatory reaction) with the development of normal immune responses and to various immunopathological conditions. The degree of manifestation of pathological changes in general, including the appearance and depth of immunopathological reactions directly depend on the intensity of action on the body of birds stimulating the growth of the apparatus of motion of anthropogenic factors, more intense and long-lasting influence is characteristic of the commodity and the human body. Adequate immunological testing is required to adequately assess the body's reserves, since the immune response system is in most cases not stable due to immunosuppressive factors in the form of immunodeficiencies. These tests are important for detecting the immunodeficiency and immunopathological conditions of the particularly latent activity of the pathogen. Studies of the immune state indicate a significant immunological restructuring in chickens with respiratory mycoplasmosis, which is manifested in significant fluctuations in leukograms and immunograms. Eosinopenia and heterophilosis were shifted to the left in the birds from breeding production farms; basophilia, monocytosis and heteropenia were shifted to the right in chickens from egg production farms, and in chickens of meat production poultry farm we registered the monocytopenia, eosinophilia and heteropenia with shift of leucoformula to the right. Immunogram analysis indicates an immunodeficiency state, functional failure of the bone marrow, disorders of polymorphonuclear leukocyte function, and a complement system, which is particularly evident in the breeding and production line of poultry.

\section{Acknowledgements}

This research work was conducted as part of the project "Criteria of morphofunctional state of compartments of barrier structures of animal organism in anthropogenically transformed ecosystems", state registration No. 0119 U001018.

\section{References}

Abbas, N., Suleman, M., Muhammad, N., Ahmad, K.N., Ali, I., Rauf, M., \& Rahman, S. (2018). Prevalence of Mycoplasma gallisepticum in poultry and wild life birds suspected of chronic respiratory disease in northern Pakistan. Journal Zoology, 50(3), 1071-1077. doi: 10.17582/journal.pjz/2018.50.3.1071.1077.

Abbas, N., Suleman, M., Muhammad, N., Rahman, S., Ahmad, K.N., Tariq, N.A., Khalid, A., \& Faheem, J. (2018). Seropositivity, involvement in suspected cases of chronic respiratory diseases and comparative efficacy of various sero-diagnostic tests of Mycoplasma gallisepticum. Journal of applied environmental and biological sciences, 8(3), 137-141.

Ahmad, A., Rabbani, M., Yaqoob, T., Ahmad, A., Shabbir, M.Z., \& Akhtar, F. (2008). Status of IgG antibodies against Mycoplasma gallisepticum in nonvaccinated commercial poultry breeder flocks. Journal of Animal and Plant Sciences, 18(2-3), 61-63.

Aleksyeyeva, N.V. (2009). Rozrobka ta udoskonalennya zasobiv specyfichnoyi diagnostyky tuberkulozu ptyci [dysertatsiia]. Odesa: Odes. derzh. agr. un-t (in Ukrainian).

Babaeva, A.G. (2009). Regeneracija: fakty i perspektivy [monografija]. Moskva: RAMN (in Russian).

Bolotnikov, I.A., \& Konopatov, Yu.V. (1993). Prakticheskaya immunologiya sel'skokhozyaistvennoi ptitsi - Practical immunology of poultry. Sankt-Peterburg: Nauka (in Russian).

Borkhsenius, S.N., Chernova, O.A., Chernov, V.M., \& Vonskii, M.S. (2002). Mikoplazmy: molekulyarnaya i kletochnaya biologiya, vzaimodeistvie i s immunnoi sistemoi mlekopitayushchikh, patogennost', diagnostika - Mycoplasmas: molecular and cellular biology, interaction with the mammalian immune system, pathogenicity, diagnostics: textbook. allowance: ucheb. posobie. Sankt-Peterburg: Nauka (in Russian).

Bøyum, A. (1976). Isolation of lymphocytes, granulocytes and macrophages. Scandinavian Journal of Immunology, 5, 9-15.

Dzhupina, S.I. (2002). Epizooticheskii protsess i ego kontrol' pri faktornykh infektsionnykh boleznyakh - Epizootic process and its control in factor infectious diseases. M.: OOO M i K (in Russian).

Gavrylin, P.M., Nedzveczkyj, V.S., Prokushenkova, O.G., \& Masyuk, D.M. (2011). Metodychni osoblyvosti zastosuvannya imunogistoximichnoyi diagnostyky cyrkovirusnoyi infekciyi. Naukovi praci Poltavskoyi derzhavnoyi agrarnoyi akademiyi. Seriya "Vetery narna medycyna", 2, 8-18 (in Ukrainian). 
Georgiades, G.K. (2002). Detection of antibodies against mycoplasma gallisepticum and mycoplasma synoviae in day-old broiler chicks and broiles. Journal of the Hellenic veterinary medical society, 53(1), 33-38. doi: 10.12681/jhvms.15357.

Horalskyi, L.P., Khomych, V.T., \& Kononskyi, O.I. (2013). Osnovy histolohichnoi tekhniky i morfofunktsionalni metody doslidzhen u normi ta pry patolohii - Fundamentals of histological technology and morphological and functional methods in patients with normal pathology Fundamentals of histological technology and morphological and functional methods in patients with normal pathology. [za red. Horalskoho LP.]: navch. posib. Zhytomyr: Polissia (in Ukrainian).

Islam, A., Aslam, A., Chaudhry, Z.I., Ahmed, M.U., Rehman, H.U., Saeed, K., \& Ahmad, I. (2011). Pathology of Mycoplasma gallisepticum in naturally infected broilers and its diagnosis through PCR. International journal of agriculture \& biology, 13(4), 835837.

Jondal, M., Okret, S., \& McConkey, D. (1993). Killing of immature CD4+ CD8+ thymocytes in vivo by anti-CD3 or 5'-(N-ethyl)carboxamide adenosine is blocked by glucocorticoid receptor antagonist RU-486. European Journal of Immunology, 23, 1246-1250.

Karaulov, A.V. (2002). Klinicheskaya immunologiya i allergologiya: ucheb. posobie - Clinical Immunology and Allergology. M.: Meditsinskoe informatsionnoe agenstvo (in Russian).

Khariv, M., Gutyj, B., Ohorodnyk, N., Vishchur, O., Khariv, I., Solovodzinska, I., Mudrak, D., Grymak, C., Bodnar, P. (2017). Activity of the T- and B-system of the cell immunity of animals under conditions of oxidation stress and effects of the liposomal drug. Ukrainian Journal of Ecology, 7(4), 536-541.

Khatoon, H., Afzal, F., Tahir, M.F., Hussain, M., \& Khan, S.U. (2018). Prevalence of Mycoplasmosis and antibiotic susceptibility of Mycoplasma gallisepticum in commercial chicken flocks of Rawalpindi division, Pakistan. Pakistan Veterinary Journal, 38(4), 446448. doi: 10.29261/pakvetj/2018.081.

Kisera, Ya.V., Storchak, Yu.G., Gutyj, B.V., Bozhyk, L.Ya., Magrelo, N., Sus, Y., Dashkovskyy, O., Pryimych, V.I., Vus, U., Kit, L., \& Sachuk, R. (2019). Structural and functional features of the vermiform appendix at the tissue and cellular levels in rabbits after the introduction of immunobiological drugs. Ukrainian Journal of Ecology, 9(2), 217-226.

Kysera, Ya.V., Storchak, Yu.G., \& Gutyj, B.V. (2018). Experimental study of immunoprophylactic anti-pneumococcal medicine and its immunogenic properties. Ukrainian Journal of Ecology, 8(1), 307-316

Majumder, S., \& Silbart, L.K. (2016). Interaction of Mycoplasma gallisepticum with chicken tracheal epithelial cells contributes to macrophage chemotaxis and activation. Infection and Immunity, 84(1), 266-274.

Majumder, S., Zappulla, F., \& Silbart, L.K. (2014). Mycoplasma gallisepticum lipid associated membrane proteins up-regulate inflammatory genes in chicken tracheal epithelial cells via TLR-2 ligation through an NF-KB Dependent Pathway. PLoS ONE, 9(11), e112796. doi: 10.1371/journal.pone.0112796.

Mathis, R., \& Ackermann, M. (2016). Response of single bacterial cells to stress gives rise to complex history dependence at the population level. Proceedings of the National Academy of Sciences of the United States of America, 113(15), 4224-4229. doi: 10.1073/pnas.1511509113.

Mendes, N.F., Tolnai, M.E., Silveira, N.P., Gilbertsen, R.B., \& Metzgar, R.S. (1973). Technical aspects of the rosette tests used to detect human complement receptor (B) and sheep erythrocyte-binding (T) lymphocytes. Journal of Immunology, 111(3), 860-867.

Much, P., Winner, F., Stipkovits, L., Rosengarten, R., Citti, C., Much, P., Winner, F., \& Citti, C. (2002). Mycoplasma gallisepticum: Influence of cell invasiveness on the outcome of experimental infection in chickens. FEMS immunology and medical microbiology, 34(3), 181-186. doi: 10.1111/j.1574-695X.2002.tb00622.x.

Muhammad, F., Alam, J., Hussain, J., Khurram, F.S., Zafar, U., Ahmed, K.S., \& Ahmad, A. (2018). Development of Elisa and its comparison with other diagnostic tests for avian mycoplasmosis. Int. Journal Biology and biotechnology, 15(1), 39-45.

Novikov, D.K., \& Novikov, P.D. (2006). Klinicheskaya immunologiya: ucheb. Posobie - Clinical immunology. Vitebsk: VHMU (in Russian).

Prokushenkova, O.G. (2014). Gistologichna ta imunologichna diagnostyka xvoroby Mareka ptyci. Naukovo-texnichnyj byuleten centru NDC biobezpeky ta ekologichnogo kontrolyu resursiv APK, 2, 129-136. (in Ukrainian).

Ron, M., Gorelick-Ashkenazi, A., Levisohn, S., Nir-Paz, R., Geary, S.J., Tulman, E., Lysnyansky, I.,\& Yogev, D. (2015). Mycoplasma gallisepticum in vivo induced antigens expressed during infection in chickens. Veterinary Microbiology, 175(2-4), 265-274. doi: 10.1016/j.vetmic.2014.12.007.

Rosengarten, R., Citti, C., Glew, M., Lischewski, A., Droesse, M., Much, P., Winner, F., Brank, M., \& Spergser, J. (2000). Hostpathogen interactions in mycoplasma pathogenesis: virulence and survival strategies of minimalist prokaryotes. International Journal of Medical Microbiology, 290(1), 15-25. doi: 10.1016/S1438-4221(00)80099-5.

Rottem, S. (2003). Interaction of mycoplasmas with host cells. Physiological Reviews, 83(2), 417-432. doi: 10.1152 / physrev.00030.2002.

Rudenko, O.P., Paranjak, R.P., Kovalchuk, N.A., Kit, L.P., Hradovych, N.I., Gutyj, B.V., Kalyn, B.M., Sukhorska, O.P., Butsiak, A.A., Kropyvka, S.I., Petruniv, V.V., \& Kovalska, L.M. (2019). Influence of seasonal factors on carp fish immune reactivity. Ukrainian Journal of Ecology, 2019, 9(3), 168-173.

Shanmugasundaram, U., Tippichettypalayam, R.G., Krishna, M., Vasudevan, G., \& Kandasamy, S. (2018). Detection of seroprevalence of Mycoplasma gallisepticum in broiler chicken in Tamil Nadu by ELISA. Journal of Entomology and Zoology Studies, 6(3), 613-614.

Thilagavathi, K., Sivaseelan, S., Balasubramaniam, G.A., \& Balasubramaniam, A. (2016). Pathology of Mycoplasma gallisepticum infection in naturally infected layer birds. Indian. Journal of Veterinary Pathology, 40(4), 337-340. doi: 10.5958/0973970X.2016.00077.8.

\section{Citation:}

Gavrilin, P.M., Alekseeva, N.V., Gavrilina, E.G., Korshenko, D.A., Kalashnik, N.V., Locieva, Y.O. (2020). Systemic immunity of chickens with respiratory mycoplasmosis at poultry farms with various production. Ukrainian Journal of Ecology, 10(1), 114-121.

\begin{tabular}{|ll}
\hline$(\mathrm{cc}) \mathrm{EY}$ \\
$\mathrm{EY}$
\end{tabular} 